

\title{
La Paradoja de la Resistencia
}

The paradox of the resistence

$\begin{array}{ll}\text { Nombre: } & \text { Lionel Brossi Garavaglia ( }{ }^{1} \text { ) } \\ \text { Filiación: } & \text { Universidad de Oxford } \\ \text { País: } & \text { España } \\ \text { Correo: } & \text { lionelbrossi@gmail.com }\end{array}$

\section{RESUMEN}

El presente artículo intenta iluminar cómo diferentes normas van circunscribiendo, modelando, e incluso modificando radicalmente nuestros cuerpos. Resistir a esas normas implicará saberse oprimido por ellas y, en cierta medida, implicará también reconocer cierto nivel de asimilación con la autoridad opresora. A través de ciertos pasajes textuales de las novelas Esclava de Nadie, la increíble historia de Elen@ de Céspedes, de Sánchez Vidal (2010), Middlesex, de Jeffrey Eugenides (2009) y Annabell, de Kathleen Winter (2011), se intenta ilustrar la noción foucaulteana en la que es a través de la rearticulación de las mismas herramientas del poder que oprime, donde pueden formularse estrategias de resistencia.

\section{ABSTRACT}

The purpose of this article, is to shed light on how different norms circumscribe our bodies, framing and even modifying them, sometimes in a radical way. To resist these norms implies to acknowledge both, the fact of being oppressed by them and at the same time, a certain level of assimilation with the oppressive power. Through different passages of the three novels Anyone's slave: the incredible story of Elen@ de Céspedes (Sánchez Vidal 2010), Middlesex (Eugenides 2003) and Annabel (Winter 2010), the intention is to illustrate the foucauldian notion that is through the rearticulation of the tools the power uses to opress bodies, that we can find a place of resistance.

PALABRAS CLAVES: Cuerpo, sexualidad, resistencia, poder.

KEYWORDS: Body, sexuality, resistance, power.

\footnotetext{
${ }^{1}$ El autor es Doctor en Teoría de la literatura y Literatura Comparada por la Universidad Autónoma de Barcelona, Barcelona, España. Actualmente es Visiting Fellow en el International Gender Studies Center de la Universidad de Oxford, UK. Sus líneas de investigación son: Estudios de Género, Literatura Comparada, Estudios Críticos del Discurso.
} 


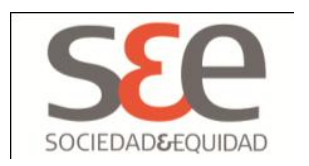

\section{Las mismas herramientas}

Al hablar de resistencia, podemos preguntarnos si ésta se sitúa dentro o fuera de las relaciones de poder-opresión y si el poder da o no fuerzas a la identidad de sí y comunitaria o solo las oprime. La resistencia surge y existe dentro de esas mismas relaciones de poder, pero en un ámbito marginal al sistema, donde marginal no funciona como "fuera de" sino "dentro de", pero en sus grietas, en sus pliegues, en sus hiancias. A lo largo de este artículo, y a través del análisis crítico de ciertos pasajes textuales de tres novelas ${ }^{2}$, se presentarán nociones conceptuales específicas que ilustran la propuesta de la "paradoja de la resistencia" en su relación con la idea de poder foucaulteana, en la que para elaborar estrategias de resistencia, se rearticulan y utilizan las mismas herramientas que el poder detenta. Las tres historias presentan varios elementos en común: el devenir sexuado de sus protagonistas que desarma el sistema binomial de sexo y género, la presión social por mantener ese sistema y la articulación de diversas formas de resistencia.

Antes de partir con la presentación de las obras citadas, es necesario detenerse en ciertos aspectos conceptuales que contribuirán a la comprensión de esta propuesta.

El saberse docilizado y controlado habilita un espacio para desarticular las interiorizaciones normativas impuestas muchas veces en forma inconsciente. Resistencia implica pensar más allá y muchas veces en contra de aquellos elementos que caracterizan la imagen clásica del pensamiento. Salirse de esos postulados, poder repensarlos y reconstruirlos, no puede hacerse sino dentro de los mismos términos en los que circula el poder.

Pensar cómo el poder hace a nuestros cuerpos más o menos visibles y en qué medida, puede revelarnos cómo éstos son manipulados por la circulación del conocimiento. El modo en que el conocimiento circula en forma performada, va imponiendo asimismo sus efectos en las sociedades, en nuestro comportamiento, en la manera en que pensamos que somos y que nos mostramos frente a l* $\mathrm{s}^{3}$ demás; en definitiva, en nuestros cuerpos.

La propuesta foucaulteana de resistencia, fue criticada por Said (Halperin, 2007) y por Baudrillard (1994) en el sentido de que la resistencia no puede ser una

\footnotetext{
${ }^{2}$ Middlesex, de Jeffrey Eugenides (2003); Esclava de Nadie: La increíble historia de Elen@ de Céspedes, de Agustín Sánchez Vidal (2010) y Annabel, de Kathleen Winter (2010).

${ }^{3}$ El uso del asterisco está implementado para evitar el uso genérico masculino. El símbolo “@” tampoco es conveniente en estos términos, ya que implica una derogada dualidad genérica y además es difícil de leer por programas utilizados por personas ciegas o ambliopes.
} 


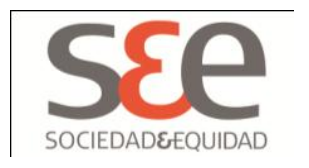

alternativa dependiente del poder y a su vez contraria, porque la circularidad de ese movimiento impediría liberarse de toda sujeción. Baudrillard, quien critica la idea de poder y represión planteada por Foucault, donde lo exterior no está al margen del poder sino en su interior, en el mismo núcleo ${ }^{4}$, sí reconoce que la resistencia es contemporánea al poder, por lo cual no es ni anterior ni posterior al mismo (Baudrillard, 1994). Foucault presenta la idea de resistencia como una práctica de lucha contra un poder opresor en forma de revolución, en donde si no se interroga cómo opera el poder, cuáles son sus condiciones de existencia y funcionalidad, la resistencia no puede tomar forma.

En los textos de Foucault, la idea de poder se presenta como aquello que es forzado por aparatos legales o institucionales. Es una circulación o distribución de conocimiento que es discursivo en su naturaleza. $Y$ en este sentido, no es concebible ningún tipo de resistencia que sea ajena a ese poder, ya que las múltiples formas de resistencia son estrategias ${ }^{5}$ de lucha dentro de esa circularidad.

La idea de represión sobre el sexo, se encuentra ligada a la exaltación de una forma de discurso que intenta develar supuestas verdades enmarcadas en un sistema binomial de sexo y género. Esos discursos modifican la economía y el porvenir de la sexualidad y se sostienen en una forma de predicación que se traduce en un agenciamiento represivo, donde se expulsan de la realidad las formas subversivas de las sexualidades periféricas (Foucault, 1995).

Al resistir ese tipo de discursos, de lo que se libera es de la libertad misma, o al menos de la noción normativa de libertad, de un tipo de libertad fraudulenta construida sobre la base de un extrañamiento del poder. Las estrategias de resistencia deben desmantelar aquellas prácticas que aparentemente liberan pero que no hacen más que producir, no ya una incertidumbre de lo que podemos hacer sino de lo que podemos no hacer; un extrañamiento de la impotencia ${ }^{6}$.

\footnotetext{
${ }^{4}$ Sobre la noción foucaulteana de poder ver Foucault (1994, 2007a, 2007b, 2008 y 2009).

${ }^{5}$ Certeau, sostiene que estrategia es el "cálculo (o a la manipulación) de las relaciones de fuerzas que se hace posible desde que un sujeto de voluntad y de poder (una empresa, un ejército, una ciudad, una institución científica) resulta aislable. La estrategia postula un lugar susceptible de circunscribirse como algo propio y de ser la base donde administrar las relaciones con una exterioridad de metas o de amenazas" de Certeau, M. (2000) La invención de lo cotidiano. Artes de Hacer. México, Universidad Iberoamericana. Instituto Tecnológico y de Estudios Superiores de Occidente. p. 42
}

${ }^{6}$ Sobre la resistencia paradójica ver Lynn Chancer, Definiendo una dinámica básica: paradojas en el corazón del sadomasoquismo en Nieto, J. A. et al. (2005) Antropología de la sexualidad y diversidad cultural. Talasa.

En relación a la resistencia como el fracaso de las fantasías identificatorias ver Butler, J. (2002) Cuerpos que importan. Sobre los límites materiales y discursivos del sexo. Buenos Aires: Paidós. 


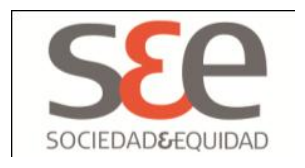

La normatividad apunta a coartar actos o libertades de los sujetos, y es el mismo poder el que proporciona la ocasión para que se manifiesten diversos tipos de resistencia. Si el poder está constituido por la circulación del discurso/saber, es a través del discurso que se resiste y que se oprime. El poder no debe ser considerado como tradicionalmente se entendía, como una especie de emanación unidireccional de autoridad, sino como el poder que es el modo en el que el conocimiento (no necesariamente de una verdad) circula e impone sus efectos en nosotr*s, en nuestros comportamientos y en las formas en que performamos nuestra sexualidad. Es desde esta noción de poder que se entiende la sexualidad como un efecto del poder del conocimiento.

Si pensamos en la noción de Esthétique de l'existence, propuesta por Michel Foucault, ésta tiene que ver con un modo de sujeción donde las personas se inscriben en un marco de valores y reglas que van a regular la estilización de la vida y asimismo la estética de la existencia. Pero no se trata de la aceptación pasiva de determinada normativa, sino de no ser esclavo ni de los otros ni de sí mismo a partir de ciertos principios generales en torno al uso de los placeres, la distribución de los mismos, su jerarquía y sus límites. Una ética de la existencia devenida en estética de la existencia (Foucault, 1976: 87).

La paradoja de la resistencia se circunscribe, entonces, en que dicha resistencia, para poder operar, debe utilizar muchas de las herramientas del sistema opresor, reconociendo de este modo la inviabilidad de una autonomía absoluta; reconociendo, finalmente, ciertos niveles de asimilación con el poder. Cuando se pide autonomía, se está reafirmando de algún modo una relación de dependencia, un tipo de vinculación con el sistema opresor que no puede ser borrado totalmente.

Es un error imaginar que se puede superar la precariedad de nuestra existencia peleando en contra de un tipo de poder exterior. La oposición a la explotación de la vulnerabilidad y a su inducción sistemática, no puede identificarse como pura actividad o como una lucha violenta que conduzca a la invulnerabilidad o impermeabilidad ante cualquier tipo de opresión. Superar nuestra propia vulnerabilidad inducida no es suficiente, porque siempre implicará nuevas manifestaciones de opresión por superar o desmantelar.

Debemos producir organizaciones políticas y sociales que hagan disponibles de una manera justa e igualitaria, formas de vida vivibles, habitables. Cuando la violencia se transforma en un acto de resistencia, si se aplica contra otras vidas humanas, termina produciendo diferentes dinámicas de violencia y aún más condiciones de precariedad.

Sobre el extrañamiento de la impotencia ver Agamben, G. (2011) Desnudez. Adriana Hidalgo Editora: Buenos Aires 




Beatriz Preciado propone que los cuerpos subversivos desterritorializan la heterosexualidad como espacio normativo, como modo de resistencia del cuerpo a ser normal (Preciado, 2008). Para ella, resistencia tiene que ver con aquel término específico que se ejerce fuera de la relación dominio y subordinación. ${ }^{7}$ Los dispositivos de producción de cuerpos "normales" no implican una imposibilidad de intervención social, subversión o contrapoder, sino que se los puede intervenir reconvirtiendo las tecnologías del cuerpo (Preciado, 2002). La idea de resistencia muta con la transformación histórico-cultural y con el aporte de nuevos discursos en torno a ella.

La relación entre experiencia, cuerpo y política, construida en base a un modelo impregnado por la heteronormatividad, debe ser desarticulada interrogando los regímenes de saber, así como también los actos performativos que los constituyen. Preciado inscribe una episteme que trasciende a la sociedad soberana y luego disciplinaria. Una tercera episteme que tiene en cuenta a las nuevas tecnologías del género, y que denomina postmoneysta, -en relación al discurso y experimentos del Dr. John Money $^{8}$ y su equipo- un régimen que implica una circulación constante de biocódigos en torno al género con técnicas flexibles, internas y asimilables, donde la resistencia a la normalización dependerá de la forma en que se reapropien dichos biocódigos (Quintana, 2010).

La nueva forma de resistencia contemporánea ${ }^{9}$ es, entonces, una forma de lucha contra la sujeción de los cuerpos, contra la sumisión de las subjetividades, contra el no saberse oprimido. Es en los cuerpos que se saben oprimidos en general, donde habita una mayor capacidad de subvertir y desinteriorizar las ideologías sesgadas del sistema patriarcal, apropiándose y reutilizando sus propios elementos para poder resistirlo.

\footnotetext{
${ }^{7}$ En una lectura foucaulteana, esta idea de "resistencia" no podría encontrarse fuera de la relación de dominio y subordinación, ya que el discurso, siempre y necesariamente está inscrito y es efecto de procesos de lucha. Tal como cita Foucault en La Voluntad del Saber (1976: 68): "donde hay poder, hay resistencia".

${ }^{8}$ A comienzos de los años setenta, John Money y Anke Ehrhardt, popularizaron la idea de que sexo y género son categorías separadas.

Ver también: Colapinto, J. (2000). The boy who was raised as a girl., Harper Collins Publishers: Nueva York

Lavigne, L. (2009). La regulación biomédica de la intersexualidad. Un abordaje de las representaciones socioculturales dominantes, Interdicciones. M. Cabral. Córdoba, Anarrés: 53-70 y también Raíces Montero, J. H. (ed.) (2010). Un cuerpo, mil sexos. Topía: Buenos Aires.

9 El rol de las nuevas tecnologías como herramientas para articular diversas formas de resistencia, ha sido importante en la apertura de la conciencia pública en torno a los sistemas de opresión, facilitando la comunicación y el intercambio de saberes y experiencias y difundiendo información para producir cambios y revertir prácticas que merman cualquier posibilidad de cohesión social.

Ver por ejemplo, Sytsma, S. (2006). Ethics and Intersex. Países Bajos: Springer.
} 


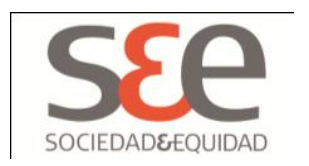

\section{Ficciones originarias}

Las novelas Middlesex, de Jeffrey Eugenides (2003); Esclava de Nadie: La increíble historia de Elen@ de Céspedes, de Antonio Sánchez Vidal (2010) y Annabel, de Kathleen Winter (2010), ofrecen determinados pasajes que dan cuenta de diversas formas de resistencia, que utilizan elementos que le son propios al poder opresivo como forma de supervivencia. Supervivencia que no implica la garantía de una vida vivible, pero sí formas en las que se articulan estrategias para hacerla posible.

En la producción académica, abundan análisis y traslados de obras literarias y películas hacia una especie de verificación o comparación con saberes científicos o discursos varios y esto no escapa a la cuestión intersex. Tal es el caso de las numerosas críticas que se han realizado, por ejemplo, en torno a las películas argentinas XXY (2007) de Lucía Puenzo, y El último verano de la Boyita (2009), de Julia Solomonof, ${ }^{10}$ sobre si su argumento es o no biologicista; si se basan en las premisas biomédicas; si cumplen o no la función de informar sobre la cuestión intersex; si reflejan las demandas de la comunidad intersex o las coartan, entre otras aproximaciones. Lo mismo ocurre, por ejemplo, con la conocida y extensamente analizada historia de Herculine Barbin $(2007)^{11}$, publicada por Michel Foucault, y más recientemente con la aquí citada Middlesex, que fue criticada, entre otras razones, porque la historia perpetuaría el discurso binomial de sexo y género o porque no respeta la terminología del activismo intersex (Carroll, 2009).

Con la revisión de las obras citadas que se presenta a continuación, no se pretende establecer una especie de verificación o diagnóstico para determinar si tal o cual obra reafirma o no cierto tipo de discursos, si promueve o no determinadas prácticas o si contradice o no ideologías o demandas. No se solicita aquí una conversación simétrica con las ficciones desde una realidad creíble, sino ilustrar algunos de sus pasajes y las potencialidades que desatan en relación a la paradoja de la resistencia, detectando aquellas vertientes de poder que a veces son invisibles a las palabras, al discurso.

Se han escogido estas novelas porque sus personajes principales, Eleno*, Cal y Annabel, para liberarse de determinados niveles de opresión en torno a su cuerpo y a su sexualidad, requerirán en el mismo momento en que se performa esa liberación,

\footnotetext{
${ }^{10}$ En relación a las críticas sobre $X X Y$ y El último verano de la boyita, ver por ejemplo: Cabral, M. (2009) Interdicciones. Escrituras de la intersexualidad. Córdoba, Anarrés: 105 y también Modarelli, A. (2010) El gozo de los raros eventos, la potencia del lenguaje: "diagnóstico" de intersexualidad en la cultura. Un cuerpo, mil sexos: Intersexualidades. Buenos Aires: Topía: 73-90.

${ }^{11}$ Para profundizar sobre el análisis y referencias a la historia de Herculine Barbin, ver: Dreguer, A. (1995), "Doubtful Sex: The Fate of the Hermaphrodite in Victorian Medicine." Victorian Studies 38(3): 335-370, y también Mélisse, L. (2002), "Uncertain Erotic: A Foucauldian Reading of herculine barbin dite Alexina B." SITES: The Journal of Contemporary French Studies 6 (1): 119-131.
} 


\section{SEe}

un sacrificio de autonomía, utilizando la misma voz de la autoridad a la que se resisten, reconociendo en ese mismo acto una asimilación de la autoridad.

En cada una de las novelas presentadas, la especificidad genérica o racial se muestra estrechamente ligada a la opresión sexual, enfatizando también la constitución mutua del género y la raza, lo que se ha dado por llamar la sexualización de la raza y la racialización del sexo (Preciado, en Carrillo 2007).

\section{La paradoja del poder}

Esclava de nadie, la increíble historia de Elen* de Céspedes, es una novela histórica en la que se reconstruye la vida de Elen* de Céspedes, a partir del expediente y testimonios conservados en el Archivo Histórico Nacional de España.

La novela se sitúa a fines del siglo XVI, cuando el inquisidor Lope de Mendoza debe juzgar a un cirujano por haber sido acusado de ser una mujer y de haber cometido el delito y la herejía de haberse casado con otra mujer, desafiando a la ley y usurpando las prerrogativas masculinas, heterosexistas y cristianas de la época. Elen* de Céspedes era hija de una esclava africana, quien fue acusada primero por la justicia laica y luego fue llevada a la cárcel en el año 1857 ante la Inquisición de Toledo. Elen* tuvo que pasar por prisiones, peritajes violentos, automutilaciones, miradas y palpaciones que intentaban definir su "verdadero sexo".

Primero, la justicia laica la acusó de usurpación del vestido masculino, por haberse casado con una mujer, y por engañar a los médicos sobre su sexo. Luego, ante la Santa Inquisición, se la acusó criminalmente por hereje, apóstata de la fe católica y evangélica o por la profunda sospecha de serlo:

-Cómo es que, siendo la acusada mujer, pudo dar a entender a tantos médicos y testigos que era varón?

Ante las dudas que creyó percibir en Céspedes, el inquisidor hizo un añadido para precisar:

-Quiero decir que no resultaría fácil engañarlos por más que disimulase su sexo y natura de mujer contrahaciéndola, arrugándola o apretándola con los lavatorios y sahumerios que al parecer hizo.

-Porque en realidad, y de verdad, soy y fui hermafrodita, con dos sexos o naturas, una de hombre y otra de mujer. [...] (Sánchez, 2010: 301).

Céspedes, para poder pasar como hombre en los peritajes médicos y de este modo evitar la hoguera y poder querellarse contra quienes le difamaron afirmando 


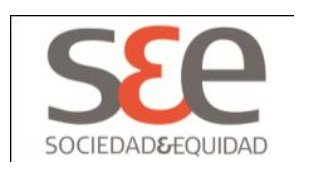

que era una mujer, decide a través de sus conocimientos de cirugía, cerrar sus labios vaginales: "Cuando lo volvió a sacar de entre las ascuas [el cauterio], ya había estudiado en el espejo los lugares donde aplicarlo para lograr unas excrecencias carnosas sobre el caño de la orina que le servirían en su demostración" (Sánchez, 2010: 236).

Es a través de una fingida mimesis, o de una performance de la categoría hombre, que Elen* intenta desafiar a quienes lo juzgaban a través de miradas y palpaciones:

Siendo mirado por éstos, de día, en la posada en la que paraba, lo tentaron y vieron por delante. Aunque presentaba un apostema, por más que lo miraron, ninguno de ellos pudo meter el dedo. Cuando los médicos preguntaron qué era aquello, él respondió que se debía a una almorrana que había tenido allí y hubieron de cauterizarle. Y más no se pudo determinar, ya que al apretar con los dedos, no entraban ni se percibía agujero alguno. Por lo que, al no poder conocer que tuviese otra natura que la de varón, todas las dichas diez personas, tanto los médicos como los demás, lo certificaron por hombre (Sánchez, 2010: 238).

Yo, Ana de Perea, aseguro que el dicho Céspedes tiene natura de mujer, y al meterle por ella una vela, entró en poca cantidad, por no estar conocida de varón, y tiene las tetas como de mujer, sin que se aprecie miembro de hombre (Sánchez, 2010: 271).

Finalmente, tras no poder comprobarse el motivo de la acusación, Elen* fue condenado a la menor de las penas: cientos de azotes y diez años de trabajo sin sueldo curando enfermos.

La excelente reputación de Elen* como cirujano era tal que luego de varios años de trabajo asalariado en un hospital, solicitaron su traslado debido a la enorme cantidad de personas que querían atenderse y curarse con él. La forma de articular su identidad en forma mimética, pareciera ser que escapa a una modalidad performativa, enfrentando y rompiendo con el contexto previo de autoridad discursiva a través del fingimiento. Sin embargo, Elen* improvisa un giro performativo, ante una amenaza de muerte o de mayor opresión, apropiándose de elementos de los mismos vectores de poder, manifestando un contrapoder con la 




realidad que invoca su performance ${ }^{12}$ que presenta una desnaturalización de la diferencia sexual ${ }^{13}$.

“[...] Trataban de reforzar la acusación de hechicería de Mantilla, vinculándola [a Céspedes] a su condición de esclava morisca, para mejor incluirla en el capítulo de pacto con el diablo. Pero Céspedes se había dado cuenta de la maniobra" (Sánchez, 2010: 282).

Elen* rompe vínculos, subvierte la erótica católica, su condición de esclava, de mujer, pero sin distanciarse de esos vínculos, sin poder alejarse de la inevitabilidad de la dependencia. El castigo inamovible como correlato de una sexualidad considerada ambigua y viciada y una descendencia indigna, de esclavos y hechiceros. La rotura de vínculos implica "mantenerse en una proximidad" ${ }^{14}$ tal que los nudos que caracterizan lo que se ha subvertido puedan retomarse de otra manera" (Allouch, 2009: 18).

Cuando se piensa en una posible rearticulación de los elementos del propio sistema para conformar las herramientas estratégicas que se utilizarán contra él, se encuentra el discurso sumergido en un proceso de luchas, donde se retoman las maniobras del oponente y se utilizan para la propia ventaja. Lo que se dice, se inscribe necesariamente en diferentes niveles, en los mismos mecanismos que se trata de denunciar o transgredir. No se trata con ello de determinar qué tan transgresora o emancipadora puede ser una acción, sino de articular cuidadosamente las estrategias para resistir al poder. Según Butler, el género no nace de una pura individualidad, sino que nuestra existencia es en gran parte constituida por normas sociales, constitutivas, a su vez, del género mismo, donde la viabilidad de nuestra individualidad depende fundamentalmente de dichas normas (Butler, 2006).

\footnotetext{
${ }^{12}$ Con el término performance nos referimos a la noción propuesta en Preciado, B. (2004). "Género y performance: tres episodios de un cybermanga feminista queer trans". Zehar. Arteleku (54).

${ }^{13}$ Esa performance se relaciona con la noción de "Quiasma" acuñada por Merleau-Ponty para referirse a la idea de la diferencia. Esta figura, que también fue revisada por Derridá y por Irigaray, refiere a un "in between", que remite en el caso de la sexualidad, ni a una diferencia ni a un sujeto masculino o femenino, sino más bien a una figura de "implicación". Ver Merleau-Ponty, M. (1968), The Visible and the Invisible. Illinois, Northwestern University Press. Y también Textures of light: Vision and Touch in Irigaray, Levinas and Merleau-Ponty. Londres y NuevaYork, Routledge.

${ }^{14}$ Esa proximidad sería, por ejemplo, el papel de la bruja en Foucault (2008), la mala cristiana, aquella que es denunciada por las autoridades, o el fenómeno periférico donde la cristianización no hincó el diente. Es decir, es la resistencia donde la proximidad crítica o el marcamiento, no es efectivo sino en tanto que lo es su proximidad.
} 


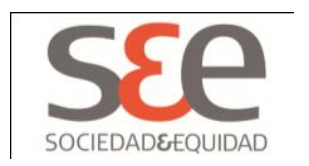

\section{La paradoja del discurso}

En Middlesex (Eugenides, 2003), tanto como en Esclava de Nadie, las narrativas de le heteronormatividad se entrelazan con la asimilación étnica. Cal, su protagonista, narra el recorrido genealógico de la historia ancestral de su familia durante nueve generaciones, que va a denominar "una historia genética"; el recorrido en montaña rusa de un gen recesivo que comienza en las hostilidades Greco-Turcas en Smyrna a principios del siglo XX, pasando por los problemas raciales en Detroit de 1967, hasta su nacimiento.

En el segundo capítulo, “Casamentera”, Cal narra: “lo único que sé es lo siguiente: pese a mi androgenizado cerebro, en la historia que voy a contar hay una innata circularidad femenina. Es una historia genética. Yo soy la última cláusula de una oración periódica cuya primera frase se escribió hace mucho tiempo, en otra lengua, y hay que leerla desde el principio para llegar al final, que es mi nacimiento". (Eugenides, 2003: 32).

En esta novela, como en las anteriormente citadas, los discursos de raza y género comparten ciertas estructuras de dominación. Por un lado encontramos la valoración negativa de los otros, la asociación de los otros con la violación de las normas, y por otro la extensión de la diferencia a una amenaza ${ }^{15}$.

La negociación de una identidad inmutable, no solo es presentada por el devenir sexuado del narrador homodiegético Cal, sino también por su calidad de inmigrante de tercera generación: "Stephanides, un norteamericano, hijo de griegos, admira a ese inmigrante turco en Alemania, a ese Gastarbeiter, por la manera en que hace el pan aquí, en Hauptstrasse, en el año 2001. Todos tenemos muchas partes, otras mitades. No sólo yo" (Eugenides, 2003: 560).

Renunciar al origen no es lo mismo aquí que renunciar a un tipo de verdad, pero sí a cualquier verdad fija como estructura centralizadora o adecuadora de la identidad. La identidad se plantea aquí como una experiencia constructa que solo se sostiene mientras se está generando (Bulo, 2009).

Largas esperas en el vestuario, la ocultación de la desnudez, la acumulación de "flotillas de tampax sin usar", el fingimiento de síntomas y fatigas, el trazado de un ciclo imaginario en el calendario de la mesa, son estrategias dolorosas que acompañarán el no saber qué está mal, el no saber qué es lo que no funciona o lo que podría no funcionar. El cuerpo y el desarrollo sexual se tornan en obsesión a medida que Cal se va acercando al momento del descubrimiento: "Programé mis

\footnotetext{
${ }^{15}$ Van Dijk, T. (1994). Discurso, Poder y Cognición Social. Conferencias de Teum van Dijk. Universidad del Valle. México. Maestría en Lingüística. Escuela de Ciencia del Lenguaje y Literaturas. 2.
} 




reglas hasta diciembre, mes en el que finalmente confiaba que finalmente hubiera aparecido la menarquia. El engaño dio resultado. Calmó la inquietud de mi madre, y en cierto modo, también la mía. Tenía la impresión de haberme hecho cargo de la situación. Ya no estaba a merced de nadie [...]" (Eugenides, 2003: 462)

Es el fingimiento de otro fingimiento; el de una femeneidad fundamental y natural. El modo en el que se inscriben los cuerpos es derivado de un contexto previo de autoridad, y para subvertirlo es necesario identificar lo ya normado para atribuirles un contrasentido a muchos valores y experiencias que damos por sentadas pero que son absolutamente cuestionables. Ante la pregunta: ¿Se resiste al poder con exigencias infinitas?, es sabido que quienes están en el poder no están en condiciones ni tienen intenciones de satisfacerlas. $Y$ es debido a que quienes detentan ese poder, saben que los oprimidos están al tanto de dicha impotencia; las exigencias infinitas no les es problemática. Para Zizek, hay que bombardear al poder hegemónico con demandas seleccionadas, precisas y finitas que no puedan ser desechadas con la excusa de la impotencia (Zizek, 2007).

Callie no menstruaba, no había desarrollado los pechos como sus compañeras de clase y sus genitales eran tal como los describía el diccionario Webster's después del vocablo hermafrodita. Fue trasladada a Nueva York con sus padres, donde luego de varios análisis, entrevistas y palpaciones, le recomendaron cirugía. En un descuido del doctor Luce, Callie tuvo acceso a su expediente clínico, en cuyo título se afirmaba "Varón genético XY, educado en sentido femenino".

Queridos papá y mamá:

Sé que sólo tratáis de hacer lo que es mejor para mí, pero no creo que nadie sepa con seguridad lo que es mejor. Os quiero y me niego a ser un problema, de manera que he decidido marcharme. Sé que diréis que no soy un problema, pero yo estoy segura de serlo. Si queréis saber porqué lo hago, preguntádselo al doctor Luce. ¿ ¿Que es un mentiroso! Yo no soy una chica. Soy un chico. Eso es lo que he descubierto hoy. Así que me voy a un sitio donde no me conozca nadie [...] (Eugenides, 2003: 559).

\section{La paradoja del deseo}

Ante el nacimiento de Wayne y el descubrimiento de su anatomía "diferente", Thomasina, una amiga de la madre, tomaba precauciones lingüísticas: "Thomasina, who, by miracles of deflection, managed to leave unspoken the first thing spoken of any newborn". La primera pregunta que imprime la vida de cualquier recién nacid*:¿Es un niño o una niña? Precauciones que en la novela Annabel (2011) de 




Kathleen Winter, se traducen en enmudecimientos, en lo no hablado o no susceptible de ser hablado.

Para el padre de Annabel, la pregunta era qué es y no qué y quién podría ser. La idea de dejar que el bebé viva tal cual nació no era una decisión posible, sino una indecisión que le causaría daño. No quería pensar en posibilidades ni las manifestaba. Sin su revólver de caza, que acostumbraba a acarrear, y aferrado a la naturaleza, subió a la montaña para, en su retiro, escuchar una respuesta.

La historia narra que Annabel nació en la primavera de 1968, en las imponentes costas canadienses de Labrador. El bebé, ante la mirada de su madre, había nacido con un testículo sin descender, un pequeño pene y una apertura vaginal.

Ante el silencio y el secretismo de su madre, Treadway, su padre, a quien hasta ahora le habían ocultado la verdad, decide que se llamará Wayne y que será criado como un hombre: "Since neither of you is going to make a decision on way or the other, he said, I'm going to make it. He's going to be a boy. I'm going to call him Wayne, after his grandfather". (Winter, 2010: 29)

La idea de un sexo verdadero que reafirma la pregunta "Es un niño o una niña?", sin posibles variaciones desde el discurso de lo masculino o femenino y basada únicamente en la configuración de los órganos genitales, es una construcción social que nos marca a tod*s y que excluye de sus derechos fundamentales a las personas que nacen con variaciones a esta norma.

A los pocos días, en el hospital, el Dr. Ho, le explica a Jacinta: "The point is to create a believable masculine anatomy. You can lay him on the operating table yourself if you like. I'll show you the exact procedure. We will show you how to wash your hands and arms and you can wear a mesk and you can watch until the point where we do the surgery itself, if you think you can stand it". (Winter, 2010: 49)

Un sexo creíble remite al privilegio de la normalidad y recae únicamente en una de las categorías: niño o niña, femenino o masculino. Es a partir de esa normalización de carácter inaugural, que emergen los problemas básicos y fundamentales que patologizan las variaciones sexuales de las personas que no se ajustan al binomio y mantienen a su vez la hegemonía heteronormativa en la sociedad.

Al medir el pene del bebé con un instrumento llamado "falómetro", el Dr. Ho confirma que la medida del órgano genital recae justo en el límite mínimo para poder criarlo como un varón $(1,5 \mathrm{~cm}$.). Wayne, más tarde Annabel, fue creciendo en una sociedad hipermasculina de cazadores, donde los roles estereotipados estaban perfectamente anclados: los hombres construyen, pescan, cazan y por lo general 


\section{SEe}

están fuera de sus casas; las mujeres se casan jóvenes, crían a sus hijos, y soportan el aislamiento y la soledad del salvaje y prístino entorno.

This was why the came here, if they came from other places such us Scotland and England and even America; they came to leave behind the collective dreams of an old world and they came to glory in their own footprints and land that have been travelled only by aboriginal peoples and the wild caribu. And if you were one of the innu or Innuit in those days, you had no need of cinema. Cinema was one of the white man's illusions to compensate for his blindness. A white man, for instance, had no idea of the life within stones. Imagine that (Winter, 2010: 56).

Estereotipos en torno al género y a la raza van trazando la trama de la diferencia, constituyendo relaciones suturadas por coerción y violencia simbólica. Mientras su padre enseñaba a Wayne a cazar, a construir con cemento, a trabajar los caminos, Jacinta y Thomasina le permitían a menudo desviarse de esos roles, como una forma de recobrar a su nunca extinguida Annabel. ¿Dónde estaba Annabel?, ¿dónde había ido? Varias píldoras diarias, verdes, amarillas y blancas, la mantenían alejada.

Wayne hizo amistad con Wally Michelin. Es con ella con quien pasaban las tardes; él dibujando puentes y Wally practicando el Cantique de Jean Racine de Fauré. El Ponte Vecchio era un pequeño puente que Wayne había construido con su padre $y$ en donde, cubriéndolo con una tela, se refugiaba con Wally. El encantamiento de Wayne por Wally, no era más que por querer ser alguna vez como ella.

Al pasar el tiempo, el cuerpo le revela a Wayne parte de su verdad: "Because his hair is soft. He has two tiny breast buds, And no Adam's apple to speak of at all" (Winter, 2010:180). A través de diccionarios, revisiones, intervenciones y explicaciones médicas y luego la confesión de Thomasina sobre su "anatomía ambigua", Wayne toma el impulso para escapar: "Dr. Likuras looked at Wayne's breasts, he saw beauty equeal to wich he would have seen in the body of any youth, male or female. It was as if he saw the apricots growing on their own tree, right where they belonged" (Winter, 2010: 212).

Decide dejar Labrador para comenzar una nueva vida en St. Jhon, donde el anonimato de la gran ciudad le daría más libertad. El abandono de las pastillas verdes, amarillas y blancas dejará que su anatomía vaya cambiando gradualmente, dejando hablar solamente a su cuerpo: "He hated the green pills. the other pills, the yellow ones and the white caspsules, were smaller. The yellow ones were tyny. He would take one a day of each of these instead of two, until they ran out. He had 


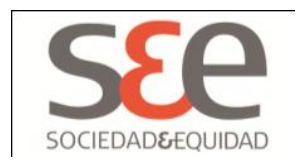

enough left that hi could do this over a month or six weeks, and if that was not gradual enough he would just have to live with whatever happened" (Winter, 2010: 354).

La transformación física fue más rápida de lo previsto. El devenir de un género al otro, de una identidad a otra, era la estrategia con la que Annabel podía sobrevivir. Al llegar a la ciudad, luego de vivir un tiempo como indigente, Annabel era explotada en un club sexual de la ciudad, mostrando dentro de una piscina su "mítica" anatomía a los clientes que se asomaban por pequeñas ventanas. Más tarde, aprovechando la oscuridad para que los clientes no reconociesen su cambio físico, Annabel repartía mercadería de una carnicería.

La exposición de su cuerpo, el tratamiento hormonal, la soledad y el alineamiento con un género o el otro, constituían elementos de los cuales Annabel buscaba liberarse, o en el mejor de los casos, alejarse lo más posible de su opresión.

En Esclava de Nadie, Middlesex y Annabel, los cuerpos de Elen*, Cal y Annabel, fueron transformados y violentados constantemente por decisiones de otr*s; decisiones cuya intención era más remover un nervio social que proteger la salud de los personajes.

La pregunta que activan las tres novelas, es la misma pregunta que Alex, protagonista de XXY (2010) formula al final de la película: ¿Y si no hay nada que decidir? Seguramente sí, para sobrevivir hay que decidir, pero la decisión debe partir desde un* mism*, no de tercer*s.

La cartografía de nuestros cuerpos, marcada histórica y culturalmente, incluso antes de nacer, muestra cómo el cuerpo es afectado por diferentes normas y discursos, produciendo una especie de exilio genérico desde que nacemos. El vocabulario compartido por las normas en torno al cuerpo lo van modelando, y es en su devenir que el cuerpo reacciona y desestabiliza el discurso. El cuerpo resiste y ante su burocratización, media la propia identidad tal como la sentimos profundamente y la identidad asignada por lo social.

Con los procesos que socializan el cuerpo, éste termina por convertirse en el lugar donde se inscriben códigos de comportamiento, códigos de vida, que muchas veces no es posible resistir o controlar debido a su extrañamiento, al no saberse normad*s, controlad*s. Para desprender el discurso binomial de nuestros cuerpos, se necesita un cambio social y cultural radical, que no refiere únicamente a articular nuevas prácticas discursivas habilitando la diversidad; implica también cuestionar cuáles son los límites simbólicos y materiales que trazan las normas en nosotr*s y cómo y porqué lo hacen.

El hecho de que la identidad tenga que pasar por palpaciones, pericias médicas, fallos y justificaciones sociales para que adquiera un estatus de legalidad, 


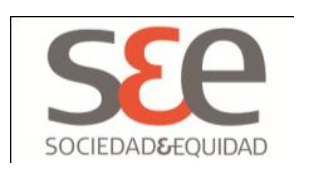

sitúa, como plantea Foucault (2008), la lógica del deseo en una posición radical de ilegalidad, donde el deseo del sujeto se concibe como algo básicamente malo. Lo oprimido y las posibilidades de resistencia nacen muchas veces de las mismas bases de sujeción. La percepción semiósica lleva consigo matices de poder, y es una habilidad necesaria de supervivencia para los cuerpos oprimidos. La confianza en quienes se desplazan por los diferentes niveles de poder (social, médico, jurídico, religioso), cargados de discursos morales paternalísticos de compasión y caridad en relación con los sujetos "menos privilegiados", puede desvanecerse o desestabilizarse a través de la concientización de cómo opera virtualmente el poder.

El ser apartado de nuestra potencialidad, permite en mayor o menor grado cierta resistencia material o ideológica; el saberse imposibilitado de hacer tal o cual cosa, el estar consciente de la privación, permite, cuando no en la práctica en el pensamiento, articular algún tipo de reacción. Pero cuando nuestro cuerpo no hace más que aceptar inconscientemente algo que no puede hacer/se o que puede no hacer/se, considerando la posibilidad o la potencialidad de esa acción como único camino, es cuando el poder se torna aún más peligroso, sin lugar para ningún tipo de resistencia, debido a que no se identifican las formas de opresión.

Las diferentes dinámicas de violencia, terminan por extender más aún la vulnerabilidad de nuestros cuerpos y las condiciones de precariedad. Los límites existen en tanto hay un afuera, un espacio lleno de significantes que debe ser abierto. Identificar esos límites que las instituciones, el Estado y la sociedad en general van imprimiendo en nuestros cuerpos, nos ayudará a convertirlos en fronteras permeables.

Habilitar las variaciones y multiplicidad de los cuerpos, así como la posibilidad de poder encarnarlos sin mermar nuestros derechos, deben ser los objetivos principales de cualquier estrategia que tienda a un cambio democrático radical en las políticas sobre el cuerpo y la sexualidad. El cuerpo liberado de los tentáculos de la ley paternal, la gran mayoría de las veces es una encarnación de las mismas normas, que en ocasiones se autodefine como subversivo pero que en realidad opera dentro de sus límites y se asimila a ellas.

Al asumir valores y tomarlos por verdaderos o unívocos, se produce lo que Agamben (2011) llama "extrañamiento de la impotencia". Es ese extrañamiento, la estrategia más fuerte del poder que -en apariencias democrática-, conduce a l*s individu*s a perder la capacidad de resistir a las normas, porque no saben lo que no pueden hacer o lo que pueden no hacer. Es necesario tomar en cuenta toda la complejidad y subterfugios de las normas, a través de las posibilidades que emergen cuando se identifican sus fisuras, produciendo cambios inesperados de sí mismas. Nuestros cuerpos, desde la normativa binomial, pasan a ser definidos más por su funcionalidad y normalidad impuesta que por las posibilidades de encarnar sus variaciones. Resistir no solo implicará identificar cómo los cuerpos son gestionados por las tecnologías de 


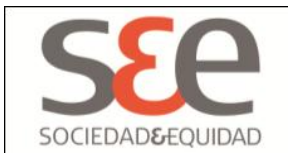

género para encajar en la trayectoria práctica y discursiva heterosexual, sino identificar también la manera en que tod*s somos categorizad*s dentro del binomio y configurad*s como sujetos de un género asignado desde el momento en que nacemos.

\section{Referencias Bibliográficas}

Agamben, G. (2011). Desnudez. Buenos Aires: Adriana Hidalgo Editora.

Allouch, J. (2009). El sexo del Amo. La sexualidad desde Lacan. Buenos Aires: El cuenco de plata.

Baudrillard, J. (1994). Olvidar a Foucault. Valencia: Pre-textos.

Bulo, V. (2009). Ontología Modal del Cuerpo en Jean Luc Nancy. Revista Philosophica 35(1): 81-94.

Butler, J. (2002). Cuerpos que importan. Sobre los límites materiales y discursivos del sexo. Buenos Aires: Paidós.

Cabral, M. (2009) .Interdicciones. Escrituras de la intersexualidad. Córdoba: Anarrés. Carrillo, J. (2007). Entrevista con Beatriz Preciado. Cuadernos Pagu [online] (28): 375-405. Recuperada

en

<http: / /www.scielo.br/scielo.php?script=sci_arttext\&pid=S0104-

$83332007000100016 \&$ Ing=en\&nrm=iso> citado el 8 de septiembre de 2011 .

Carroll, R. (2009). Retrospective Sex: Rewriting Intersexuality in Jeffrey Eugenides's Middlesex. Journal of American Studies 44(1): 187-201.

Colapinto, J. (2000). The boy who was raised as a girl. Nueva York: Harper Collins Publishers.

Dreguer, A. (1995). Doubtful Sex: The Fate of the Hermaphrodite in Victorian Medicine. Victorian Studies 38(3): 335-370.

Eugenides, J. (2003). Middlesex. Barcelona: Picador.

Foucault, M. (2009). Vigilar y Castigar. Madrid: Siglo XXI.

Foucault, M. (2008). Los Anormales. Buenos Aires: Fondo de Cultura Económica Argentina S.A.

Foucault, M. (2007b). El Nacimiento de la Biopolítica. Buenos Aires: Fondo de la Cultura Económica Argentina S.A.

Foucault, M. (2007a). Herculine Barbin, llamada Alexina B. Madrid: Talasa

Foucault, M. (1995). Historia de La Sexualidad. La voluntad del Saber. Madrid: Siglo XXI. 


\section{s\&e \\ SOCIEDADEEQUIDAD}

Foucault, M. (1994). Un diálogo sobre el Poder. Barcelona: Atalaya.

Halperin, D. (2007). San Foucault. Para una agiografía gay. Buenos Aires: Ediciones Literales.

Lavigne, L. (2009). La regulación biomédica de la intersexualidad. Un abordaje de las representaciones socioculturales dominantes. Interdicciones. M. Cabral. Córdoba, Anarrés: 53-70.

Mélisse, L. (2002). Uncertain Erotic: A Foucauldian Reading of herculine barbin dite Alexina B. SITES: The Journal of Contemporary French Studies 6 (1): 119-131.

Merleau-Ponty, M. (1968) The Visible and the Invisible. Illinois: Northwestern University Press.

Modarelli, A. (2010). El gozo de los raros eventos, la potencia del lenguaje: "diagnóstico" de intersexualidad en la cultura. Un cuerpo, mil sexos: Intersexualidades. Buenos Aires, Topía: 73-90.

Nieto, J. A. et al. (2005). Antropología de la sexualidad y diversidad cultural. Madrid, Talasa.

Preciado, B. (2004). Género y performance: tres episodios de un cybermanga queer trans. Zehar. Arteleku (54).

Preciado, B. (2008). Testo Yonki. Madrid: Espasa Calpe.

Preciado, B. (2002). Manifiesto contra-sexual. Madrid: Opera Prima.

Quintana, I. (2010). Biopolítica. Mora (B. Aires) [online]. 16 (2 ) [citado 2011-09-14]. Recuperado en: <http://www.scielo.org.ar/scielo.php?script=sci_arttext\&pid=S1853001X2010000200015\&lng=es\&nrm=iso>. ISSN 1853-001X.

Raíces Montero, J. H. (2010). Un cuerpo, mil sexos. Buenos Aires: Topía.

Sanchez Vidal, A. (2010). Esclava de Nadie. La increíble historia de Elen@ de Céspedes. Madrid: Espasa.

Shostak, D. (2008). Theory Uncompromised by Practicality: Hibridity in Jeffrey Eugenides' Middlesex. Contemporary Literature 49 (3): 383-412.

Systma, S. (2006). Ethics and Intersex. Países Bajos: Springer.

Van Dijk, T. (1994). Discurso, Poder y Cognición Social. Conferencias de Teum van Dijk. Universidad del Valle. México. Maestría en Lingüística. Escuela de Ciencia del Lenguaje y Literaturas. 2. 


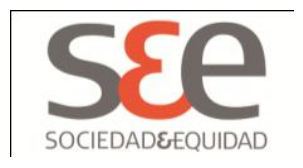

Vasseleu, C. (1998). Textures of light: Vision and Touch in Irigaray, Levinas and Merleau- Ponty. Londres y Nueva York: Routledge.

Winter, K.(2010). Annabel. A novel. Nueva York: Black Cat.

Zizek, S. (2007). Resistance is Surrender. London Review of Books 29, 7 